\title{
EL TROCADERO: DATAS PARA CARENAS Y ALMACENES (1739-1845) ${ }^{1}$
}

\section{JUAN JOSÉ IGLESIAS RODRÍGUEZ | UNIVERSIDAD DE SEVILLA \\ ORCID iD: 0000-0002-3692-4761}

\begin{abstract}
RESUMEN
El traslado a Cádiz de la capitalidad del comercio colonial planteó la necesidad de activar una logística de apoyo para la Carrera de Indias. El tráfico naval entre la metrópoli y las colonias exigía disponer de almacenes para los pertrechos navales y de instalaciones para las carenas de los buques mercantes. Los navieros y comerciantes gaditanos encontraron un lugar idóneo para ello en el caño del Trocadero, situado en el seno interior de la bahía de Cádiz. A pesar de que se trató de un derecho cuestionado por el Consulado de mercaderes y por las autoridades del departamento naval, el ayuntamiento de Puerto Real hizo uso de los viejos privilegios fundacionales de la villa para conceder terrenos destinados a almacenes y carenas a los particulares y compañías que los solicitaron.
\end{abstract}

PALABRAS CLAVE

Carrera de Indias, arsenal naval, carenas, almacenes de pertrechos, datas de terrenos, siglos XVIII y XIX.

\section{THE TROCADERO: LAND CONCESSIONS FOR CAREEN AND WAREHOUSES}

\begin{abstract}
The transfer to Cadiz of the colonial trade centre necessitated the development of port infrastructure that would ensure logistical assistance for the Carrera de Indias. Maritime traffic between the metropolis and the colonies became so complex that they required warehouses for naval supplies as well as facilities to careen merchant vessels. Shipowners and traders from Cadiz found Trocadero, inside the Bay of Cadiz, an ideal place to establish such facilities. Despite criticism from the Consulate and the authorities of the naval department, the local government of Puerto Real drew on the town's old foundational privileges to grant land for naval storage and careens to those individuals and companies that requested them.
\end{abstract}

\section{KEYWORDS}

Carrera de Indias, naval arsenal, careen, warehouses, land concessions, 18th and 19th centuries.

1 El presente trabajo se enmarca en el Proyecto ANDATLAN:“La construcción de un mundo nuevo: circuitos económicos, dinámicas sociales y mediadores culturales en las ciudades atlánticas del sur de España, siglos XVI-XVIII" (HAR201785305-P), financiado por el Ministerio de Ciencia e Innovación del Gobierno de España dentro del Plan Estatal de I+D+i. 


\section{EL TROCADERO, CARENERO DE LA CARRERA DE INDIAS}

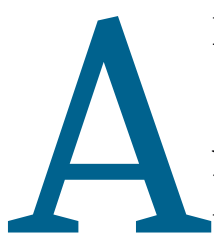

1 asumir la capitalidad del tráfico colonial, el comercio gaditano se enfrentó a nuevas necesidades y exigencias, que a su vez forzaron reajustes ineludibles y rápidas adaptaciones ${ }^{2}$. Entre aquellas necesidades figuró la de disponer de una base logística eficaz para hacer frente al crecimiento de la demanda de carenas para los buques de la Carrera de Indias y de almacenes para la custodia de aparejos y efectos navales. Este, el de las infraestructuras portuarias de la Carrera, es un tema poco estudiado y al que venimos prestando atención desde hace ya algún tiempo ${ }^{3}$. Entre ellas, hemos incidido en el papel de las construidas en el caño del Trocadero, el cual proporcionó una respuesta válida, aunque no exenta de problemas y dificultades, a aquellas necesidades de carena y almacenamiento ${ }^{4}$. El Trocadero se transformó así en un vital espacio estratégico para el comercio colonial y, por extensión, para el comercio atlántico, que también encontró allí unas instalaciones útiles para el mantenimiento y la reparación de sus barcos. Junto a la Carraca, el Trocadero configuró en la bahía de Cádiz un eje de gran valor para la política atlántica española: el uno como arsenal naval de la Carrera de Indias; la otra, como uno de los grandes arsenales de la marina de guerra española, en este caso el vinculado al departamento marítimo gaditano ${ }^{5}$.

Al menos desde mediados del siglo XVII, el Trocadero se venía utilizando como lugar de carenas. Sin embargo, esta actividad no había generado aun el desarrollo de infraestructuras estables. Así lo demuestra un mapa del seno interior de la bahía de Cádiz trazado en 1668 de orden del duque de Alcalá, capitán general del Mar Océano y Costas de Andalucía. Dicho mapa pone de relieve la utilidad del caño como ancladero de navíos, representada por dos

2 El libro de BUSTOS RODRÍGUEZ, Manuel. Cádiz en el sistema atlántico. La ciudad, sus comerciantes $y$ la actividad mercantil (1650-1830). Madrid: Sílex, 2005. es una obra fundamental para comprender el marco general en el que se inscribe esta aportación.

3 IGLESIAS RODRÍGUEZ, Juan José. El complejo portuario gaditano en el siglo XVIII. En: e-Spania. [en línea]. 2016, nº 25, en línea. ISSN-e: 1951-6169. Disponible en: https://journals.openedition.org/e-spania/25989. IGLESIAS RODRÍGUEZ, Juan José. Las infraestructuras portuarias gaditanas ante el reto del monopolio gaditano. En: Studia Histórica. Historia Moderna, 2017, vol. 39., n 2, pp. 185-219. https://doi.org/10.14201/shhmo2017392.

4 IGLESIAS RORÍGUEZ, Juan José. El Trocadero en la política atlántica en la Edad Moderna. En ÁLVAREZ SANTALÓ, León Carlos (coord.). Estudios de Historia Moderna en homenaje al Profesor Antonio García-Baquero. Sevilla: Universidad de Sevilla, 2009. pp. 141-158. IGLESIAS RODRÍGUEZ, Juan José. ·El "canal prodigioso": el caño del Trocadero en el siglo XVIII. En: Matagorda. 2015, $\mathrm{n}^{\circ}$ 1. pp. 47-77. ISSN: 2444-2437.

5 CRESPO SOlANA, Ana. La Casa de Contratación y la Intendencia General de la Marina en Cádiz (1717-1730). Cádiz. Universidad de Cádiz, 1996. QUINTERO GONZÁLEZ, José. La Carraca: un arsenal para la política naval de Felipe V. En: PEREIRA IGLESIAS, José Luis (coord.). Felipe V de Borbón, 1701-1746. Córdoba. Universidad de Córdoba y Ayuntamiento de San Fernando, 2002. pp. 685-707. KHUETE, Alan J. y ANDRIEN, Kenneth. J. The Spanish Atlantic World in the Eighteenth Century. War and the Bourbon Reforms, 1713-1796. New York. Cambridge University Press, 2014. 
barcos, uno fondeado en sus aguas y el otro anclado en su orilla, y también como carenero, a tenor de la siguiente leyenda explicativa que en él figura: "En este caño del Trocadero dan carena nauíos". Ambas orillas del caño aparecen empero desnudas de edificios, salvo el castillo o fuerte de Matagorda, erigido en sus inmediaciones, y un molino mareal construido en un brazo del propio caño, como se refleja en otro mapa conservado en el Archivo Histórico Nacional (figura 1).

En el siglo XVIII, las bondades naturales que ofrecía el caño del Trocadero para la flota mercante fueron elogiadas, con elocuentes términos, por los navieros gaditanos, quienes, en un informe al Consulado, se referían a él como el "canal prodigioso", estimando, quizás con exageración, que, una vez realizadas las obras necesarias, sería capaz para acoger hasta doscientos bajeles ${ }^{6}$. Pero el caño se situaba en una zona de marismas recubierta de fangos que dificultaban construir en sus orillas. Constituía, además, la arteria principal de una red de caños y cañuelos secundarios (caños de María, de Juan Abril, de los Ingleses...), que zigzagueaban por su banda norte y complicaban aun más la intrincada geografía del territorio que ocupaba. En la banda sur se extendía un islote pantanoso, al que las fuentes denominan en ocasiones isla de San Luis o de Fort-Luis, abierto a la bahía interior a través de extensos playazos y bajíos.

De estas dificultosas condiciones del terreno derivaron las grandes inversiones que fueron necesarias para la puesta en marcha y el mantenimiento del Trocadero como infraestructura portuaria para la Carrera de Indias. Quizás por esta razón, su utilización como lugar ocasional de carenas no generó un asentamiento estable hasta bien entrado el siglo XVIII, permaneciendo hasta entonces "desierta de edificios y gente toda aquella ribera", según el citado informe de los propietarios de navíos de la Carrera, que data el comienzo de la construcción de instalaciones a orillas del caño en el año $1743^{7}$.

El propósito de este artículo es realizar una primera aproximación al proceso histórico de ocupación del Trocadero, a través de las datas de terrenos concedidas por el Ayuntamiento de Puerto Real, en cuyo término municipal se encontraba y se encuentra este caño. Dicha documentación, aunque insuficiente por sí sola y necesitada de completarse con otras fuentes, representa una extraordinaria muestra del interés suscitado por instalarse en el caño por parte de los comerciantes y navieros gaditanos activos en la Carrera

6 IGLESIAS RODRÍGUEZ, Juan José, El “canal prodigioso...", p. 71-72.

7 Archivo General de Indias (AGI), Consulados, 1367, $\mathrm{n}^{\circ} 2$. 
de Indias, de las variaciones que aquel proceso sufrió en el tiempo y de la específica problemática que conllevó.

\section{Figura 1}

Plano de la bahía de Cádiz (finales del siglo XVII)

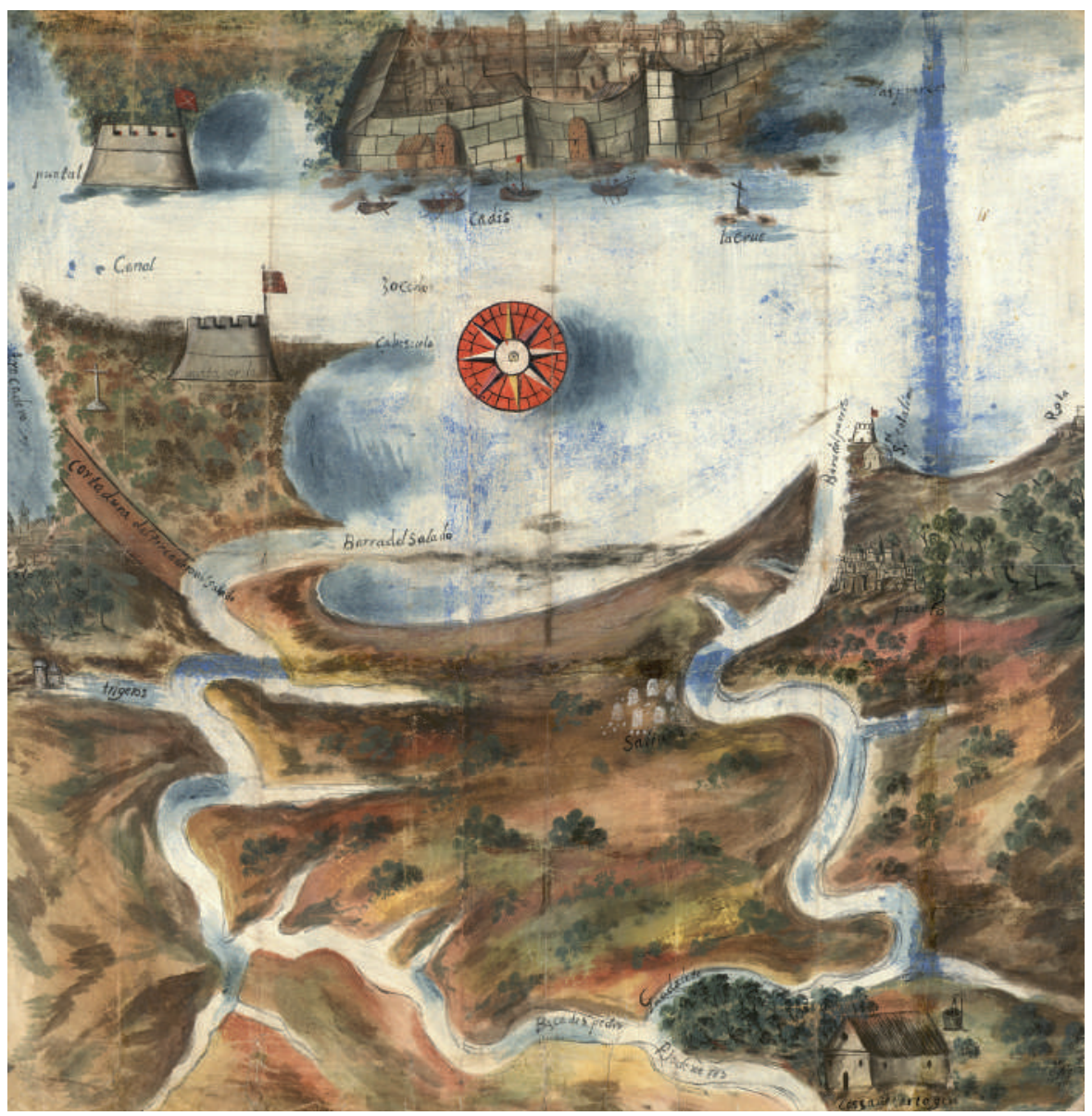

Fuente: Archivo Histórico Nacional, Consejos, MPD. 1779

\section{LA LEGÍTIMA FACULTAD PARA LAS DATAS}

El caño del Trocadero estaba situado en terrenos baldíos pertenecientes al término municipal de Puerto Real. La Casa de la Contratación se arrogó el derecho a conceder terrenos a particulares en sus orillas para que construyesen allí diques y almacenes, al considerar que, estando destinado al comercio de Indias, el Trocadero caía bajo su directa jurisdicción. Por la misma razón, también el Consulado de cargadores a Indias otorgó permisos similares a 
algunos de sus integrantes y otros interesados ${ }^{8}$. Sin embargo, el Ayuntamiento de Puerto Real hizo prevalecer los antiguos privilegios de la villa para reclamarse titular legítimo del derecho a conceder datas de tierras en el Trocadero. Tales privilegios estaban incluidos en la carta puebla fundacional otorgada por los Reyes Católicos, la cual contenía dos cláusulas que amparaban la mencionada prerrogativa: una que facultaba a la justicia y regidores de la villa para dar a los nuevos moradores el suelo que necesitasen para edificar casas y roturar tierras, y otra que condicionaba los derechos así adquiridos por los pobladores a la efectiva construcción de aquellas casas y plantío de las tierras en un tiempo preestablecido de entre uno y dos años ${ }^{9}$. Este privilegio fue posteriormente confirmado, a petición de la villa, por todos los sucesores en el trono de los citados monarcas.

Fue por esta razón por la que los candidatos a radicarse en el Trocadero apelaron al favor de la villa puertorrealeña. Temerosos de que sus nuevas propiedades y los cuantiosos capitales que habían invertido en ellas pudieran verse en entredicho, incluso aquellos que habían obtenido terrenos en el Trocadero mediante concesión de la Casa de la Contratación o del Consulado de cargadores a Indias acudieron posteriormente al Ayuntamiento de Puerto Real para ratificar la data. No fue este, desde luego, el caso del propio Consulado, cuya instalación en el Trocadero vino determinada por el asiento para la gestión de los navíos de aviso entre España y las colonias que esta institución mercantil suscribió con el gobierno de la Monarquía en $1720^{10}$, no constando que solicitara a tal fin la correspondiente data de terreno al cabildo puertorrealeño. Pero sí el de diversos comerciantes particulares que acudieron en primera instancia al tribunal de la Contratación o al propio Consulado y más tarde al municipio para asegurar la propiedad de los terrenos que habían ocupado.

8 Entre 1758 y 1779 se elevaron al Consulado hasta 18 solicitudes de permiso para la instalación de almacenes, tinglados, herrerías y otras dependencias. En la lista de solicitantes figuran Manuel Rivero e Hijos, Pedro Nicolás Tardy, Tomás Micón, el marqués de Casa Arizón, Pedro Vélez, Francisco Antonio de los Hoyos, Félix Almerá, Luis Segundo de Arístegui, Alonso José García, Fernando Álvarez, Ignacio de Garay y Pablo Mayo. AGI, Consulados, 1368, nº 2.

9 "... e dende en adelante que la justicia e regidores del puedan dar e den a cada un vezino que alli viniere a morar el suelo que razonablemente oviere menester para fazer e labrar su casa e el suelo e sitio que cada uno fuere dado e señalado para fazer y hedificar cassa en la forma susodicha Nos por esta carta lo concedemos e damos e otorgamos. E otrosi es nuestra merced que todos aquellos a quien fueren señalados e dados suelos e sitios para edificar cassas en la dicha villa las fagan e pueblen dentro de un año e aquellos a quien fueren dados suelos para plantar arboles o viñas los planten dentro de dos años e si assi no lo fizieren que pierdan los suelos e se puedan dar e den con esta misma condicion". Vid. MURO OREJÓN, Antonio. La villa de Puerto Real, fundación de los Reyes Católicos. En: MURO OREJÓN, Antonio. Puerto Real en los siglos modernos. Edición y estudio introductorio a cargo de J. J. Iglesias Rodríguez. Sevilla: Editorial Universidad de Sevilla, 2019, pP. 31-48.

10 VALLEJO GARCÍA-HEVIA, José María. Los navíos de aviso y los correos marítimos a Indias (1492-1898). En: Ius fugit. 1998, nº 7, pP. 197-268. ISSN: 1132-8975. 
Así lo hizo, por ejemplo, Félix Almerá, dueño de un navío de la Carrera de Indias, quien obtuvo licencia de la Casa de Contratación para ocupar un terreno de cien varas frente al caño, en el que construyó un almacén para los pertrechos de su navío, maderas para sus carenas y abrigo de las maestranzas, todo ello, según su propia declaración, de buena fe y sin conocimiento de que la propiedad de los terrenos pertenecía a la villa de Puerto Real en fuerza de los privilegios concedidos por los Reyes Católicos. En 1761 formalizó la data de dicha parcela y de diez varas más de frente ante el cabildo puertorrealeño ${ }^{11}$. Otro caso similar fue el del marqués de Casa Arizón, el cual comenzó a construir almacenes y diques en el Trocadero con permiso del Consulado, suspendiendo las obras cuando tuvo conocimiento de que la capacidad para conceder los terrenos correspondía al Ayuntamiento de Puerto Real, y hasta tanto no obtenía de este la procedente data ${ }^{12}$. Por el contrario, la compañía de Manuel Rivero e Hijos, una de las que mayor presencia tuvieron en el Trocadero, solicitó permiso para levantar almacenes y tinglados al Consulado, que este organismo le concedió en 1759 con la condición que de manera general impuso la Casa de la Contratación de dejar 60 varas expeditas entre la orilla del caño y lo que se construyese ${ }^{13}$, pero no consta que esta compañía acudiera después al Ayuntamiento de Puerto Real para solicitar formalmente la data.

Ala inversa, algunos de los comerciantes que obtuvieron del municipio puertorrealeño datas de terrenos en el Trocadero acudieron posteriormente a la Corona para que les confirmara su posesión. Inquietos por los conflictos jurisdiccionales planteados entre el Ayuntamiento y los órganos rectores del comercio con Indias, y preocupados por las crecidas inversiones que habían realizado en el caño, buscaban de este modo una seguridad que hasta entonces no sentían. Tal fue el caso de Francisco Fernández de Ahedo, de Juan Esteban de Goyena o de Tomás de Apodaca. Los dos primeros obtuvieron reales provisiones que confirmaban las datas que habían conseguido; sin embargo, la solicitud de Apodaca dio origen a que se llevara a cabo una averiguación sobre este asunto, ordenando en 1762 el Consejo de Castilla al alcalde mayor de Puerto Real y al gobernador de Cádiz que informasen sobre el particular ${ }^{14}$.

Tales informes tuvieron un sentido opuesto. El alcalde de Puerto Real, Fernando González de Socueva, se mostró disconforme con que el municipio continuara concediendo datas en el

11 Archivo Municipal de Puerto Real (AMPR), caja 1206. “Autos de data a don Phelix de Almerá en el Caño del Trocadero de este término".

12 Ibídem.

13 AGI, Consulados, $1368, n^{\circ}$ 2. "Expediente a instancia de varios individuos de este vecindario y comercio sobre que se les conceda permiso para labrar algunos almacenes en el caño del Trocadero" (1758).

14 AGI, Consulados, Libro 714. 
Trocadero en fuerza de los privilegios de la villa. En su opinión, esta práctica era contraria al espíritu de estos privilegios, pues, lejos de fomentar el aumento de la población, contribuía a disminuirla, dado que los almacenes de jarcias y pertrechos navales que existían en Puerto Real se estaban trasladando al Trocadero en detrimento de la villa. Por otra parte, sostuvo que los Reyes Católicos habían concedido facultad al gobierno municipal para dar terrenos al objeto de construir casas y labrar tierras, no para la finalidad que pretendían los comerciantes gaditanos $^{15}$. Este criterio puede parecer paradójico, pues era el propio Ayuntamiento, a cuya cabeza figuraba Socueva, el que estaba procediendo a realizar las datas. Sin embargo, como alcalde mayor y capitán a guerra de la villa, Socueva ejercía temporalmente su cargo por nombramiento real y era ajeno a los intereses de la oligarquía local puertorrealeña de regidores perpetuos, élite de poder celosa del cumplimiento de los privilegios locales y activa defensora de estos ${ }^{16}$.

Por el contrario, el gobernador de Cádiz, José de Sentmanat, se mostró claramente favorable a la utilización del Trocadero por el comercio gaditano. Informó al Consejo de que anteriormente las carenas de los navíos mercantes se hacían en el caño de Arillo, en la Isla de León, mientras que las reparaciones de los buques de la Armada real se realizaban en el Puente Zuazo, hasta que se trasladaron a la Carraca ${ }^{17}$. Desde unos años atrás, sin embargo, las carenas de los barcos de la Carrera de Indias habían pasado a efectuarse en el caño del Trocadero, con gran provecho para la villa de Puerto Real, que había visto incrementada su población. Una vez establecidas allí las carenas, los dueños de navíos mercantes comenzaron a construir almacenes para la custodia de sus pertrechos, ahorrándose de este modo los costes que antes les suponía tenerlos en Puerto Real, la Isla de León y otros lugares. El

15 Ibídem. Copia del informe elevado por Fernando de Socueva y Fustero, 25 de febrero de 1763.

16 Fernando de Socueva era caballero veinticuatro de Sevilla y había sido nombrado alcalde mayor el 21 de diciembre de 1761. En el momento de emitir su informe al Consejo apenas llevaba, pues, dos años residiendo en Puerto Real. González de Socueva fue autor de una Introducción manual para la más breve expedición de los casos prácticos $\gamma$ disputas de inmunidad local (Sevilla, 1766). Vid. MURO OREJÓN, Antonio. Puerto Real en el siglo XVIII. Noticias documentales para una Historia de la Real Villa. En: MURO OREJÓN, Antonio. Puerto Real en los siglos modernos, pP. 49-115, 62. También es obra de González de Socueva un Estado actual de los censos mas frequentes en este revno, $\gamma$ aquel, a que deben reglarse sus reditos $\gamma$ condiciones (Sevilla, Imprenta de D. Joseph Navarro y Armijo, s. a.). HERRERA MORILLAS, J. L. y CAVERO COLL, Juan Pedro. Libros impresos en Sevilla durante los siglos XV a XVIII, conservados en las bibliotecas universitarias de Andalucía. En: Boletín de la Asociación Andaluza de Bibliotecarios. 2002, nº 68, pp. 37-66. ISSN: 0213-6333.

17 En su Discurso de la fundación y antigüedades de Cádiz, (1591), Agustín de Horozco escribió sobre el caño de Arillo que "es tan abundante de agua que parece un muy buen río en que puede nadar navío de más de 150 toneladas". HOROZCO, Agustín de. Historia de Cádiz. Edición de A. Morgado García. Cádiz: Universidad de Cádiz, 2000, p. 176. Por su parte, fray Jerónimo de la Concepción se refiere al Puente Zuazo como invernadero de la Armada Real. CONCEPCIÓN, Jerónimo de la. Emporio del Orbe. Edición de A. Morgado García. Cádiz: Universidad de Cádiz, 2004, p. 96. En el Puente Zuazo se encontraba el Real Carenero de la Armada Real desde al menos el siglo XVI. Vid. QUINTERO GONZÁLEZ, José. Jarcias y lonas. La renovación de la Armada en la Bahía de Cádiz. 1717-1777. Cádiz: Grupo Publicaciones del Sur, 2003, pp. $35-45$. 
Consulado a Indias, encargado del despacho de $\operatorname{los}$ avisos ${ }^{18}$, fue de los primeros en construir almacenes y, a imitación suya, lo siguieron la Real Compañía de Caracas y diversos particulares ${ }^{19}$.

En realidad, la intervención del Consejo tenía como finalidad averiguar si las datas de terrenos en el Trocadero podían producir algún provecho para la Real Hacienda, sujetándolos a tributo. No lo consideraba así Sentmenat, quien pensaba que, tratándose de terrenos pantanosos e inundables por las crecientes del mar, nadie pagaría por ellos, puesto que para consolidarlos se consumían mucho mayores cantidades que los siete reales de vellón en los que los alarifes de Puerto Real habían tasado cada vara cuadrada ${ }^{20}$. Sin embargo, no debió ser así, dado el interés mostrado por los comerciantes y navieros gaditanos en instalarse en aquel paraje.

Las datas de terrenos que efectuaba el Ayuntamiento de Puerto Real eran gratuitas. La villa no percibía nada por estas concesiones, pero sus regidores, además de la defensa de los viejos privilegios fundacionales de la población, debían sin duda tener otros intereses menos explícitos. Muchos de ellos estarían vinculados a los grandes comerciantes gaditanos a través de las redes relacionales que estos manejaban, basadas en lazos familiares, intereses mercantiles e intercambios de favores. El obsequio también formó parte de la fórmula, como demuestra una carta de Tomás de Apodaca a Fernando de Socueva, el alcalde renuente a la construcción de almacenes en el Trocadero, en la que, tras agradecerle los favores que le debía por ocuparse de asuntos de su interés, le escribía:

"Me tomo la licencia de remitir a V. M. con el portador esta alhajita para que, siendo de su aceptación, se sirva destinarla a mi Sra. $D^{a}$ Baltasara, a cupos pies me repito para que logre yo la satisfacción de que V. M. me considere como su más apasionado $\gamma$ reconocido, $\gamma$ que en esta calidad ejercite $\gamma$ o mi verdadera obediencia en cuanto fuere de su major servicio" ${ }^{21}$.

\footnotetext{
18 Sobre el Consulado remitimos a la excelente obra de BUSTOS RODRÍGUEZ, Manuel. El consulado de cargadores a Indias en el siglo XVIII (1700-1830). Cádiz: Editorial UCA, 2017.

19 AGI, Consulados, Libro 714. Copia del informe de José de Sentmanat, 7 de septiembre de 1764.

20 Ibídem.

21 AGI, Consulados. Libro 714. "Cartas y cuentas concernientes a la medición del terreno del Caño del Trocadero, informe al Concejo y compra de plazas en la villa de Puerto Real, año 1762". Tomás de Apodaca a Fernando Socueva y Fustero. Cádiz, 10 de diciembre de 1762.
} 
Estas líneas, significativamente, se escribieron justamente cuando pendía el informe que el Consejo le había ordenado enviar al alcalde mayor de Puerto Real sobre las datas de terrenos en el Trocadero, a raíz de la instancia que el propio Tomás de Apodaca había elevado al rey.

\section{LA CRONOLOGÍA Y LOS BENEFICIARIOS DE LAS DATAS}

Como se ha expresado anteriormente, según consta en una representación de diversos propietarios de navíos de la Carrera de Indias al Consulado gaditano la fábrica de almacenes, obradores y otros edificios en el Trocadero dio comienzo en el año $1743^{22}$. Esta fecha resulta verosímil como indicativa del momento en el que los comerciantes y propietarios de navíos particulares empezaron a asentarse en las orillas del caño, pero es preciso tener en cuenta dos circunstancias. Una, que es altamente probable que el Consulado viniera realizando las carenas de los navíos de aviso a su cargo en el Trocadero desde una fecha anterior. La segunda, que ya unos años antes, en 1739, se localiza la primera data en el caño por parte del Ayuntamiento de Puerto Real para la construcción de un almacén de pertrechos. El solicitante fue el capitán de navío mercante José del Duque, vecino de Cádiz, quien pidió 150 varas de terreno en la banda norte del Trocadero, al este del caño María ${ }^{23}$. Es muy posible, sin embargo, que este almacén no llegara a construirse. También aquel año de 1739 se concedió una data a Manuel de Herrera, quien actuaba en representación de Nicolás de Moya, pero en este caso fue para la construcción de un molino.

La orden de que no se hiciera fuego a bordo motivó que diversos propietarios de navíos solicitaran terrenos en el Trocadero para establecer en ellos instalaciones auxiliares para las carenas. La brea que se utilizaba en estas labores se solía cocer hasta entonces en las mismas embarcaciones. En ellas también se cocinaba la comida de las maestranzas. Ello conllevaba un alto riesgo de incendios, que podían propagarse con facilidad a otras naves cercanas surtas en el caño. La prohibición de hacer fuego obligaba a disponer en tierra de cocinas y cocederos de brea, necesidad que concurría también con la conveniencia de establecer almacenes para el resguardo de los pertrechos. El temor a los incendios constituyó una constante a lo largo de la historia del carenero, reflejada en numerosos documentos del Consulado.

22 AGI, Consulados, 1367, nº 1. Representación de los dueños de navíos de la Carrera de Indias al presidente de Contratación, 13 de enero de 1777.

23 AMPR, caja 1205. "Autos hechos en razón de una data de tierra en el Caño del Trocadero dada por esta villa a Don Joseph del Duque, vecino de la ciudad de Cádiz". 
Fue precisamente la prohibición de encender fuego a bordo de los barcos en carena el motivo que alegó el comerciante portuense Francisco Fernández de Ahedo para solicitar en 1743 la data de un terreno de 70 varas de frente y otras tantas de fondo en el Trocadero ${ }^{24}$. Fernández de Ahedo construyó también el que probablemente fue el primer dique de carenas del caño propiedad de un particular y segundo tras el del Consulado ${ }^{25}$. Asimismo, construyó varios almacenes y un muelle de cantería ${ }^{26}$. A esta data siguieron otras: las de Francisco de Alzáybar, Ignacio de Garay y Tomás de Apodaca en la década de los cincuenta; o las concedidas al marqués de Casa Arizón, Félix Almerá, José Sánchez de Madrid, Francisco de Tabernilla, Domingo de Olea y Manuel de Soto en la década de los sesenta, que fue la que más registró en total ${ }^{27}$. En estos años no sólo se establecieron en el caño comerciantes y propietarios de navíos. Las labores de carena y la construcción de almacenes demandaban también gran cantidad de clavos y herrajes, cuya provisión corrió a cargo de las herrerías que también se radicaron en el Trocadero. Con este fin solicitaron datas de suelo los herreros Pedro Gómez, Manuel de Ortega y Cristóbal Pérez. Asimismo, la afluencia de las maestranzas y del personal de los almacenes generó una incipiente demanda de servicios. Así, Pedro Vélez solicitó una data en 1753 para establecer una taberna.

A partir de los años setenta del siglo se observa una ralentización de las datas. Influyó en este hecho que el Trocadero experimentase ya un importante nivel de ocupación, como demuestra la cartografía de la época (figura $n^{\circ} 2$ ), así como también la limitación impuesta por el Consulado de dejar un espacio expedito de 60 varas de ancho en cada banda del caño. Pero, sobre todo, el hecho determinante fue el creciente interés del gobierno por aprovechar para la Marina de guerra y otros usos las posibilidades que ofrecía el Trocadero. De hecho, en ambas bandas del Trocadero mantuvo el rey posesiones. En la banda norte, la Marina real dispuso de un arsenal completo para carenas y el rey se hizo allí mediante compra con la propiedad de diversos almacenes. En el lado opuesto, la Real Hacienda almacenó y custodió los azogues que se remitían a Indias. Por último, el rey dispuso también de una batería en la entrada del Trocadero para la defensa del caño y del seno interior de la bahía ${ }^{28}$.

24 Ibídem. "Autos en razón de una data de tierra en el Caño del Trocadero a don Francisco Fernández del Haedo". Este personaje aparece en el Catastro de Ensenada como navegante a Indias avecindado en El Puerto de Santa María, con unas utilidades anuales estimadas en 30.000 reales de vellón. IGLESIAS RODRÍGUEZ, Juan José. Una ciudad mercantil en el siglo XVIII. El Puerto de Santa María. Sevilla: Muñoz Moya y Montraveta editores, 1991, p. 314.

25 En una carta de Ciprián Autrán a Esteban José de Abaria, fechada el 13 de marzo de 1755, se especifica que, en la parte norte del Trocadero, Fernández de Ahedo tenía unos almacenes y, contiguo a ellos, "una grande excavación que ha hecho para formar un dilatado dique". AGI, Consulados, $1368, \mathrm{n}^{\circ} 7$.

26 AGI, Consulados, $1367, \mathrm{n}^{\circ} 1$.

27 AMPR, cajas 1205 y 1206.

28 AGI, Consulados, 1369. Borrador de carta de los cónsules Jorge de Araurrenechea y Pedro de Murguía a D. Manuel Gonzáles Guiral. Cádiz, 23 de julio de 1797. 
La única data que concedió el municipio puertorrealeño en la década de los setenta fue, de hecho, la de unas albinas y caños que solicitó Francisco Guerra de la Vega con el fin de aprovechar el movimiento de las mareas para el funcionamiento del molino que poseía en el Trocadero ${ }^{29}$. En la década de los ochenta, José de Molina aún consiguió una concesión de terrenos para almacenes y diques de maderas; pero, cuando el propio Guerra de la Vega pretendió una nueva data para la construcción de almacenes, el ministro de Marina, el bailío Antonio Valdés, comunicó al Ayuntamiento de Puerto Real una orden del rey anulando la concesión "por ser perjudicial a los intereses del rey y objeto de Marina tan importantes a todo el Estado" ${ }^{30}$. Por primera vez, en esta real orden se cuestionaban los privilegios de la villa concedidos por los Reyes Católicos, aludiendo a la diferencia de la época en las que fueron otorgados con la vigente y, por tanto, a su manifiesta obsolescencia. No dejaba de ser un síntoma del cambio de los tiempos y de los nuevos aires que soplaban en la política española.

A pesar de ello, todavía en la década final del siglo el Ayuntamiento de Puerto Real procedería a nuevas datas. En 1790 concedió los terrenos abandonados por el marqués de Casa Arizón a Joaquín de Abarca, quien los solicitó en nombre de Manuel Sánchez de la Vega para instalar una tienda y almacén. El mismo año se formalizaba la data de los terrenos que la Compañía de La Habana ocupaba en el caño desde 1744. Y en 1792 se le ampliaron a José de Molina los que le habían sido concedidos ocho años antes, si bien la Junta del Departamento naval paralizó las obras de los almacenes que este propietario estaba realizando y el capitán general de la Armada, Luis de Córdova, recordó al Ayuntamiento de Puerto Real la orden real de 1790 y le ordenó no realizar en lo sucesivo más datas ${ }^{31}$.

Añadidas a esta prohibición, la crisis del comercio colonial que sobrevino en la coyuntura de cambio de siglo y la ocupación francesa durante la guerra de la Independencia fueron las causas determinantes de que se detuviera la concesión de datas en el Trocadero. Este último conflicto dejó las instalaciones levantadas en el caño en una situación de franco

29 AMPR, caja 1206. "Autos de data de un terreno y albina en el Caño del Trocadero de este término a Francisco Guerra de la Vega". Este molino perteneció con anterioridad al suegro de Guerra de la Vega, Francisco de Tabernilla. Francisco Guerra de la Vega, comerciante, naviero, industrial y hacendado, tuvo una presencia muy activa en el Trocadero. IGLESIAS RODRÍGUEZ, Juan José. La burguesía atlántica gaditana del siglo XVIII: visiones del mundo y transformaciones de mentalidad. En: IGLESIAS RODRÍGUEZ, Juan José y GARCÍA BERNAL, José Jaime (eds.). Andalucía en el mundo atlántico moderno. Agentes y escenarios. Madrid: Sílex, 2016, pp. 355-388.

30 AMPR, caja 1207. "Terrenos cedidos gratis a don Francisco Guerra de la Vega".

31 Ibídem. "Expediente formado en razón de haberse mandado parar la obra que estaba haciendo don Joseph de Molina en un terreno que se le concedió en data por el ayuntamiento en el sitio del Caño del Trocadero, término y jurisdicción de esta villa". 
deterioro, debido al saqueo de los almacenes por las tropas ocupantes ${ }^{32}$. Pasada la destructiva marea napoleónica, de nefastas consecuencias para Puerto Real ${ }^{33}$, el Trocadero dio algunas débiles muestras de recuperación. El Ayuntamiento de la villa, tenaz en la defensa a ultranza de los privilegios fundacionales, retomó la concesión de datas en el caño. En 1814, apenas acabada la guerra, concedió un terrero a Juan de Mora para que estableciera una herrería. Un año después, Juan Antonio de la Vega solicitaba y conseguía suelo para un almacén de pertrechos navales, en nombre de Antonio Figueroa, primer piloto de la Carrera de Indias. También en 1815 se le concedieron terrenos al fabricante de jarcias Ramón Sánchez, así como a Nicolás Ladero (que actuaba en representación de José Vivancos) para otro almacén de pertrechos ${ }^{34}$. El Trocadero parecía renacer de sus cenizas. Incluso, aparecieron ciertas rivalidades entre propietarios que apuntan a una revalorización del lugar. Así, diversos dueños de almacenes se unieron para oponerse enérgicamente a la data de un terreno situado delante de sus instalaciones ${ }^{35}$.

Sin embargo, la invasión de los Cien Mil Hijos de San Luis y la nueva ocupación francesa del Trocadero, ahora por las tropas del duque de Angulema, unida a los negativos efectos del proceso de independencia de las colonias americanas ${ }^{36}$, sellaron un nuevo momento de decadencia y un giro en la trayectoria histórica de este lugar ${ }^{37}$. El abandono del Trocadero como carenero de la Carrera de Indias estuvo unido a la desaparición de esta última. Síntoma inequívoco es el hecho de que las escasas datas de terrenos en aquel paraje en fechas posteriores a la emancipación de las colonias lo fueran para actividades muy diferentes a las que se habían desarrollado en las orillas del caño hasta entonces: la ganadería ${ }^{38}$ o la explotación de salinas ${ }^{39}$. Otro indicio de esta realidad es que el Diccionario de Madoz, en

32 IZCO REINA, Manuel Jesús y ESPINOSA DE LOS MONTEROS, Francisco. Matagorda, 1810: un episodio de la Guerra de la Independencia en Andalucía. Puerto Real: Ayuntamiento, 2012.

33 PIZARRO FERNÁNDEZ, José. José Napoléon I en Puerto Real y la Nación española en Cádiz; 1810-1812. Cádiz, 2012, especialmente, pP. 12-41.

34 AMPR, caja 1207.

35 Ibídem. Año 1822. “Expediente formado para conceder un pedazo de tierra en el Caño del Trocadero a Francisco Armario".

36 GARCÍA-BAQUERO GONZÁLEZ, Antonio. Comercio colonial y guerras revolucionarias. La decadencia económica de Cádiz a raíz de la emancipación americana. Sevilla: Escuela de Estudios Hispano-Americanos, 1972.

37 CASTRO, Adolfo de. Historia del Trocadero y Matagorda, hoy dique de la Compañía Trasatlántica. Cádiz: Tipografía Gaditana, 1896.

38 AMPR, caja 1207. Año 1829. “Data de un pedazo de tierra a Josefa Rodríguez en el sitio del Trocadero para majadal de sus ganados".

39 En 1845, Juan Suárez dueño de la salina establecida en el Trocadero llamada "San Luis", solicitó un terreno aledaño a la misma. AMPR, caja 1571. 
la entrada que dedica al Trocadero, se refiera sólo a las características geográficas del lugar, sin apuntar a la existencia allí de actividad económica alguna ${ }^{40}$.

Una nueva etapa sobrevendría para el Trocadero a partir de 1845, pero ya de la mano de la época industrial. En aquel año se registra la última data realizada por el municipio puertorrealeño en el caño, a solicitud de Juan Luis de Somavía, del comercio de la ciudad de Cádiz, quien, en unión de otros socios, compró los almacenes que habían sido de la Compañía de Filipinas con la idea de establecer un dique o carenero para buques mercantes en el islote de Fort-Luis. Para ello, solicitó al Ayuntamiento de Puerto Real el resto de los terrenos que la villa tenía en aquel lugar, apelando a las ventajas que este dique reportaría a la población, puesto que "además de utilizar del mejor modo posible un terreno que hoy nada le produce, tendrá indudablemente ocupación para muchos de sus vecinos que hoy carecen de ella" 41 . El Ayuntamiento y los mayores contribuyentes respaldaron con entusiasmo esta iniciativa, dado el estado de penuria en que se encontraban los operarios de maestranza, "que antes formaba en sus jornales la principal riqueza de este pueblo", así como el conjunto de la población desde la invasión napoleónica ${ }^{42}$. Los terrenos pretendidos por Somavía, un total de cuatro aranzadas, fueron apreciados en 1.000 reales de valor en venta, y cedidos a este, que actuaba en representación de la Sociedad Gaditana del Trocadero, a cambio de un censo perpetuo al tres por ciento anual.

\section{Tabla 1}

\section{Datas de terrenos en el Trocadero}

\begin{tabular}{|c|c|c|c|c|c|}
\hline No & Año & Nombre & Profesión & Finalidad & Observaciones \\
\hline 1 & 1739 & José del Duque & $\begin{array}{c}\text { Capitán de } \\
\text { navío mercante }\end{array}$ & $\begin{array}{c}\text { Almacén de } \\
\text { pertrechos }\end{array}$ & \\
\hline 2 & 1739 & $\begin{array}{c}\text { Manuel de } \\
\text { Herrera }\end{array}$ & Molino de pan & $\begin{array}{c}\text { Cedido a Nicolás de } \\
\text { Moya }\end{array}$ \\
\hline \multicolumn{5}{|r}{} \\
\hline \multicolumn{3}{|r}{ Continúa en la siguiente página... } \\
\hline
\end{tabular}

40 MADOZ, Pascual. Diccionario geográfico-estadístico-histórico de España y sus posesiones de Ultramar. Madrid, 18451850. Utilizamos la edición facsímil para la provincia de Cádiz realizada por Ámbito Ediciones en 1986, p. 294.

41 AMPR, caja 1571, exp. 2.

42 Ibídem. 


\begin{tabular}{|c|c|c|c|c|c|}
\hline 3 & 1743 & $\begin{array}{l}\text { Francisco } \\
\text { Fernández del } \\
\text { Ahedo }\end{array}$ & Comerciante & $\begin{array}{l}\text { Almacén de } \\
\text { pertrechos }\end{array}$ & \\
\hline 4 & 1752 & Pedro Gómez & Herrero & Herrería & \\
\hline 5 & 1752 & $\begin{array}{c}\text { Francisco de } \\
\text { Alzáybar }\end{array}$ & Comerciante & Almacén y carenas & \\
\hline 6 & 1752 & $\begin{array}{l}\text { Manuel de } \\
\text { Ortega }\end{array}$ & Herrero & Herrería & \\
\hline 7 & 1753 & Pedro Vélez & Tabernero & Taberna & \\
\hline 8 & 1758 & $\begin{array}{l}\text { Manuel } \\
\text { Ardanás }\end{array}$ & & Almacenes & $\begin{array}{c}\text { En nombre de Ignacio } \\
\text { de Garay }\end{array}$ \\
\hline 9 & 1758 & Cristóbal Pérez & $\begin{array}{c}\text { Cerrajero y } \\
\text { armero }\end{array}$ & Herrería & \\
\hline 10 & 1759 & $\begin{array}{l}\text { Tomás de } \\
\text { Apodaca }\end{array}$ & Comerciante & Almacén y diques & \\
\hline 11 & 1761 & $\begin{array}{l}\text { Marqués de } \\
\text { Casa Arizón }\end{array}$ & Comerciante & Almacén y diques & \\
\hline 12 & 1761 & $\begin{array}{l}\text { Francisco } \\
\text { Fernández del } \\
\text { Ahedo }\end{array}$ & Comerciante & Diques y almacenes & $\begin{array}{c}\text { Formalización de una } \\
\text { data de } 1752\end{array}$ \\
\hline 13 & 1761 & Félix Almerá & $\begin{array}{l}\text { Comercio de } \\
\text { Indias }\end{array}$ & $\begin{array}{c}\text { Almacén y dique } \\
\text { para maderas }\end{array}$ & \\
\hline 14 & 1761 & $\begin{array}{c}\text { José Sánchez de } \\
\text { Madrid }\end{array}$ & $\begin{array}{l}\text { Comercio de } \\
\text { Indias }\end{array}$ & Almacén de carenas & \\
\hline 15 & 1762 & $\begin{array}{c}\text { Francisco de } \\
\text { Tabernilla }\end{array}$ & $\begin{array}{l}\text { Comercio de } \\
\text { Indias }\end{array}$ & Carenas & \\
\hline \multicolumn{6}{|c|}{ Continúa en la siguiente página... } \\
\hline
\end{tabular}




\begin{tabular}{|c|c|c|c|c|c|}
\hline 16 & 1763 & Félix Almerá & $\begin{array}{l}\text { Comercio de } \\
\text { Indias }\end{array}$ & Almacén y dique & $\begin{array}{c}\text { Ampliación de la data } \\
\text { de } 1761\end{array}$ \\
\hline 17 & 1763 & $\begin{array}{l}\text { Domingo de } \\
\text { Olea }\end{array}$ & Comerciante & Carenas & \\
\hline 18 & 1767 & Manuel de Soto & Comerciante & $\begin{array}{l}\text { Almacenes de } \\
\text { pertrechos }\end{array}$ & \\
\hline 19 & 1776 & $\begin{array}{c}\text { Francisco } \\
\text { Guerra de la } \\
\text { Vega }\end{array}$ & $\begin{array}{l}\text { Comerciante e } \\
\text { industrial }\end{array}$ & Molino & \\
\hline 20 & 1784 & José de Molina & & $\begin{array}{c}\text { Almacenes y diques } \\
\text { para maderas }\end{array}$ & \\
\hline 21 & 1789 & $\begin{array}{c}\text { Francisco } \\
\text { Guerra de la } \\
\text { Vega }\end{array}$ & Comerciante & Almacenes & \\
\hline 22 & 1790 & $\begin{array}{c}\text { Joaquín de } \\
\text { Abarca }\end{array}$ & & Tienda y almacén & $\begin{array}{l}\text { En nombre de Manuel } \\
\text { Sánchez de la Vega }\end{array}$ \\
\hline 23 & 1790 & $\begin{array}{l}\text { Real Compañía } \\
\text { de La Habana }\end{array}$ & & Almacén y carenas & $\begin{array}{c}\text { Instalada en el } \\
\text { Trocadero desde } 1744\end{array}$ \\
\hline 24 & 1792 & José de Molina & & Almacén y dique & \\
\hline 25 & 1814 & Juan Mora & Herrero & Herrería & \\
\hline 26 & 1815 & $\begin{array}{c}\text { Juan Antonio } \\
\text { de la Vega }\end{array}$ & & $\begin{array}{l}\text { Almacén de } \\
\text { pertrechos }\end{array}$ & $\begin{array}{c}\text { En nombre de Antonio } \\
\text { Figueroa }\end{array}$ \\
\hline 27 & 1815 & $\begin{array}{l}\text { Ramón } \\
\text { Sánchez }\end{array}$ & $\begin{array}{l}\text { Fabricante de } \\
\text { jarcia }\end{array}$ & Fábrica de jarcia & \\
\hline 28 & 1815 & Nicolás Ladero & & $\begin{array}{l}\text { Almacén de } \\
\text { pertrechos }\end{array}$ & $\begin{array}{c}\text { En nombre de José } \\
\text { Vivancos }\end{array}$ \\
\hline
\end{tabular}




\begin{tabular}{|c|c|c|c|c|c|}
\hline 29 & 1815 & $\begin{array}{l}\text { Marcelino } \\
\text { Balbás }\end{array}$ & & $\begin{array}{c}\text { "Nuevo } \\
\text { establecimiento" }\end{array}$ & \\
\hline 30 & 1822 & $\begin{array}{l}\text { Francisco } \\
\text { Armario }\end{array}$ & & $\begin{array}{c}\text { Construcción de una } \\
\text { casa }\end{array}$ & \\
\hline 31 & 1829 & $\begin{array}{c}\text { Josefa } \\
\text { Rodríguez }\end{array}$ & & Majadal & \\
\hline 32 & 1845 & Juan Suárez & & Salina & \\
\hline 33 & 1845 & $\begin{array}{c}\text { Juan Luis de } \\
\text { Somavía }\end{array}$ & Comerciante & Dique o carenero & $\begin{array}{c}\text { En nombre de la } \\
\text { Sociedad Gaditana del } \\
\text { Trocadero }\end{array}$ \\
\hline
\end{tabular}

Fuente: Archivo Municipal de Puerto Real, cajas 1205, 1206, 1207, 1571 y 2344

\section{CONCLUSIONES}

El desplazamiento paulatino de la cabecera de las flotas de Indias hacia las aguas de la bahía gaditana incrementó la demanda de carenas y almacenes de pertrechos navales en esta área para el uso de la marina mercante. El carenero del Puente Zuazo y el río Arillo oficiaron respectivamente como lugares de carenas de los buques de las armadas y de los barcos menores del comercio. Los de mayor tonelaje encontraron, por su parte, un lugar idóneo para las invernadas en el caño del Trocadero, en términos de Puerto Real, que ya desde mediados del siglo XVII operó como surgidero y como carenero de los navíos de la Carrera de Indias, sin que por ello se desarrollaran por el momento instalaciones estables en sus orillas ni un núcleo de población consolidado. El traslado oficial de la cabecera de las flotas y el de los órganos rectores del comercio americano desde Sevilla a Cádiz consagraron en las últimas décadas de aquel siglo y las primeras del XVIII un proceso de basculación de la capitalidad del tráfico colonial hacia Cádiz y su bahía, generando nuevas demandas en la logística de apoyo a la navegación entre España y América.

A pesar de las dificultades derivadas de la naturaleza cenagosa del terreno, el Trocadero se convirtió así en el arsenal naval de la Carrera de Indias. La instalación en sus orillas del Consulado de cargadores, que asumió el asiento de los navíos de aviso, es- 
timuló el interés de las compañías de comercio y de los propietarios particulares de embarcaciones de la Carrera por disponer de almacenes y diques de carena en el caño. Obtuvieron permiso para ello de la Casa de la Contratación o del propio Consulado, pero desde el primer momento el Ayuntamiento de Puerto Real hizo valer sus privilegios fundacionales, otorgados por los Reyes Católicos a fines del siglo XV, para conceder datas de terrenos realengos en el término de la villa a quienes quisiesen avecindarse en ella y contribuir al aumento de su población. Desde 1730, el cabildo puertorrealeño se erigió de este modo en un agente activo del proceso de ocupación del Trocadero por el comercio gaditano.

Un proceso que no estuvo exento de problemas ni conflictos. La villa de Puerto Real se reclamaba titular de los terrenos y de la jurisdicción sobre quienes lo habitasen, por estar el caño situado en su término y en fuerza de sus antiguos privilegios. Los organismos rectores del comercio colonial, la Casa de la Contratación y el propio Consulado de cargadores, entendían por su lado que tenían competencias jurisdiccionales sobre el Trocadero por tratarse de un lugar vinculado a la organización del tráfico americano. Sobre este trasfondo de tensiones, el empeño de la Corona de utilizar el Trocadero para los intereses de la Armada y de la Real Hacienda produjo un cambio sustancial en la situación, llegando incluso a interrumpir las datas del municipio puertorrealeño, el cual resistió el cumplimiento de la real orden y se esforzó para que sus privilegios se vieran reconocidos y se mantuviesen en vigor.

En las décadas finales del siglo XVIII, en tiempos ya del libre comercio, el Trocadero alcanzó su mayor nivel de ocupación y actividad, y se abrió también a la demanda de carenas de las embarcaciones del tráfico europeo internacional. La crisis del comercio colonial, las dos sucesivas ocupaciones militares francesas de 1810-1812 y 1823 y la emancipación de las colonias americanas precipitaron, sin embargo, su decadencia. El posterior resurgimiento estaría ya ligado a las transformaciones de la era industrial: las carenas de barcos de vapor, la llegada del ferrocarril, las masivas exportaciones de una industria bodeguera de corte capitalista y, posteriormente, el desarrollo de la construcción naval, con la puesta en funcionamiento, en el paraje aledaño de Matagorda, del dique de la Compañía Transatlántica, una de las grandes industrias paradigmáticas de la bahía gaditana en los tiempos contemporáneos. 
Figura 2

Plano del Trocadero, 1786

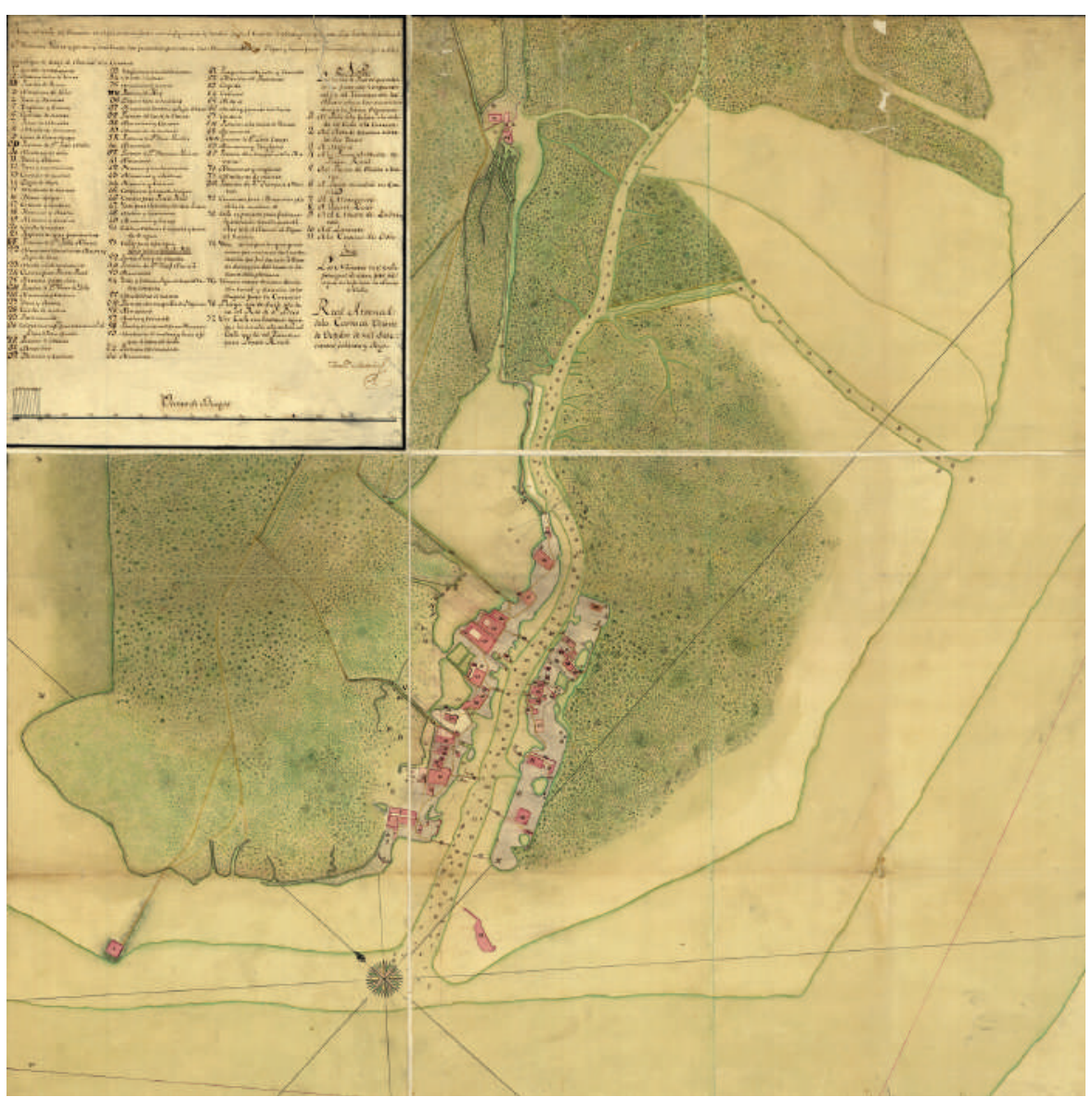

Fuente: Archivo Cartográfico y de Estudios Geográficos del Centro Geográfico del Ejército 